\title{
Patterns of Divorce Risk in the 1970s and 1980s for Swedish Women with a Gymnasium Education
}

\author{
HONG YING
}

Doctoral Student

Demography Unit

Stockholm University,

Stockholm, Sweden

\begin{abstract}
This paper investigates the first-marriage divorce patterns of Swedish women with a gymnasium education. We have used a hazard regression model to investigate the impact of a number of variables on divorce risks. Our general findings are consistent with previous studies: divorce risks have a strong negative relationship with age at marriage and with parity, and those who have premarital children or are pregnant at marriage have higher divorce risks than those who do not. The divorce risk increased over the cohorts born between 1948 and 1963. Important new findings are (i) that the risk of divorce varies with educational orientation, (ii) that within educational groups, women from an academic gymnasium have a lower divorce risk than those from a vocational gymnasium, (iii) that in each educational group, the risk varies inversely with the proportion of women employed.
\end{abstract}

Keywords: divorce, divorce risk, education, educational orientation women, employment, hazard regression model, Sweden

\section{Introduction}

There are many studies which investigate the effect of educational attainment on family disruption or divorce (see for example, Bumpass and Sweet 1972; Houseknecht and Spanier 1980; Maneker and Rankin 1985; Bracher et al. 1993; Blossfeld et al. 1993; Hoem 1995a). Most of them have found a relatively strong effect of education on divorce. The extent and the direction of the effect vary according to social context. It is a shortcoming that almost all of these studies of divorce have represented educational attainment only through educational level. The effects of the other side of education, i.e. its orientation, have been neglected and our knowledge about its effect on divorce is quite limited. From a comprehensive perspective, the effect of education on the risk of divorce may work through both the level of education and the orientation of education. The level of education is often regarded as a proxy of earning power, opportunity, and social status. On the other hand, educational orientation is closely related to occupation, working environment, sector of employment and occupational competi- 
tion in the labor market and all of these aspects may cause problems in the family and affect marriage stability (Philliber and Hiller 1983).

The present paper aims to investigate the impact of educational orientation on the risk of divorce (i.e. the legal end) of a first marriage and, in particular, on whether it is an important explanatory factor of divorce for Swedish women with a gymnasium education. This investigation is an extension of a study by Hoem (1995b), who focuses on the divorce risk of Swedish women with a postgymnasium education.

According to the life-cycle approach which we follow, marriage is affected by different factors and marriage itself may serve a different purpose at different stages of a marriage. Empirical studies suggest that the risk of divorce varies correspondingly over the duration of marriage (Maneker and Pankin, 1985; South and Spitze 1986). In line with this, I investigate whether the effects of other factors change with the duration of marriage by examining the effect of marriage duration in conjunction with other factors used in this study. I also do the same to the effect of birth cohort since the process of growth of different birth cohorts is associated with different social and economic environments, which may also modify the effect of other factors on the risk of divorce.

The main focus of this paper is on the effects of educational orientation on the risk of divorce. The mechanisms of "self-selection" into a particular kind of education and of the "protection" of the professions corresponding to the educational orientations were suggested by Hoem (1995b) as a first explanation of the finding that the risk of divorce depends more strongly on educational orientation than on the level of education for Swedish women with a postgymnasium education. In the present study, I further test this explanation by analyzing how divorce risks vary across educational orientations according to whether the orientation leads to an occupation that is traditionally dominated by women, and also according to whether it is a vocational education or an academic education. The effect of the length of gymnasium education is also taken into account.

I have paid much attention to the gender composition of those pursuing various kinds of gymnasium education, in particular whether the schooling itself is dominated by women or by men. Philliber and Hiller (1983) divided occupations into traditionally and nontraditionally female according to whether the occupations were primarily dominated by men or by women. In this study I adopt their distinction and expect to find that women who have been trained for typically female jobs, such as a caring profession, have lower divorce risks, and that women trained for typically male occupations, such as technicians and transportation workers, have higher divorce risks. This expectation is mainly based on the consideration that the educational orientation should be closely related to the sector of employment and occupation, and the fact that whether a woman is employed in a traditionally female occupation has been found to affect the probability of divorce even more strongly than the status of the wife's job (which is generally regarded as a proxy for educational level) in the United States (Philliber and Hiller 1983). It is also possible that a woman in a male-dominated occupation has a better chance of meeting a new irresistibly attractive man, which may hurt the current marriage.

In addition, the above expectation is also generated by the assumption that women who choose to be trained for a typically male occupation may have stronger gender-equality norms and have less fear than others of competition with men in the labor market, and conversely for those who are trained for typically female occupations. The type of education women choose, and corresponding occupational experiences, may in turn strengthen their original norms. The difference of values and norms may further contribute to the risk of divorce, since the cost of divorce for a woman with stronger traditional values may be higher. 
Presumably, a more educated woman may be more attractive to a partner, at least so long as we only consider education up through the gymnasium level. Hence a higher divorce risk is expected for women who have graduated from a two-year gymnasium stream than for women from a corresponding three-year stream. This hypothesis is also based on the fact that a negative divorce-risk gradient by educational attainment exists for Swedish women for at least some of our period of observation (Blossfeld et al. 1993; Hoem 1995b).

Choosing an academic stream or a vocational stream for one's education seems to be related to a woman's socioeconomic background. Girls from working-class families are more likely to choose vocational training, and girls from upper classes are more likely to select the academic streams (SCB, 1995). Previous studies have found that for Swedish women in the 1970s and early 1980s, the risk of divorce rose with the socioeconomic status of the family (Trussell, Rodriguez and Vaughan 1992). This should work toward a higher risk of divorce for women who have graduated from an academic stream.

Finally I expect to find a less dramatic effect of educational orientation on divorce risk for women with a gymnasium education than that found by Hoem (1995b) for women with a postgymnasium education because the connection between education and occupation is weaker at the gymnasium level.

Although whether a marriage ends in divorce or not depends on a wide range of factors, the final decision is generally made through rational estimation aiming to reach the best possible self-interest (in both the material and psychological sense). In this paper I adopt the general cost-benefit approach to explain the divorce behavior of Swedish women with a gymnasium education. The microeconomic theory of marriage holds that a couple will divorce if the value of staying married is lower than the sum of outside opportunities (Becker 1981; Weiss 1993). The sociological approach, based on the sociological exchange theory of rational action, views a couple as rationally trying to get what they need by exchanging valued resources with each other. Divorce will be pursued if the disadvantages of current marriage exceeds its advantages (Levinger 1979). According to these two approaches, divorce may be viewed as a result of a rational calculation of the costs and benefits of continuing the current marriage versus alternatives (including non-marriage) and in the light of marriage-specific capital investment. Factors that may play a role in the process of rationality include the couple's own characteristics, experiences before marriage, circumstances surrounding marriage, and the barriers to and predicted consequences of divorce.

\section{Method and data}

Our method of analysis is a piecewise-constant proportional-hazard regression model. In the current study, exposure is measured as the number of months since firstmarriage formation, and the impact of other variables on divorce is measured by means of their relative risks of divorce. In some cases, interactions between factors are included to improve our understanding of the forces at work.

The data are derived from two registers, both organized by Statistics Sweden. The first is the Fertility Register, which contains the month and year of occurrences of all registered demographic events, such as marriage, childbearing, divorce and death, during the period 1961-1991 for all women born after 1924 who were Swedish citizens and domiciled in Sweden in 1960, and for the Swedish-born daughters of these women. The divorce records are reliable from 1968 on. The second data set is the Register of Education, which contains detailed information about each individual's certificates and degrees as well as the specialization as recorded in 1990. The target group contains 
about 255,000 women, which constitutes 46.8 percent of the total number of marriages derived from the two data sets.

The covariates included in the analysis are summarized below:

Covariates

Time-fixed covariates

Cohort (year of birth)

Age at marriage

Educational orientation

Premarital birth

Pregnant at marriage

Time-varying covariates

Parity

Duration of marriage

(in ordinal years)
Levels

1944-1963, in two-year groups

20-23, 24-28, 29-35

27 groups (see Table 1)

no, yes

no, yes

$0,1,2,3+$;

$1-2,3-4,5-7,8-10,11-14,15-20$

I restrict the investigation to women born in the years from 1944 to 1963 who completed their education with a gymnasium degree. Women who married after the age of 35 have been omitted from the analysis because those who married at unusually high ages may have special patterns of divorce. Because Swedes normally finish their gymnasium education in their late teens, I have also excluded those who first married before age 20 , in order to reduce any possible effect of reverse causation. For example, women who first married as teenagers may have had to divorce in order to continue their education (Hoem 1995c).

In the Swedish educational system, the gymnasium degree includes both academic and vocational streams. Most of the streams take two or three years to complete. This analysis is restricted to women who stopped their education after these two or three years of gymnasium. Education has been classified into twenty-seven groups, taking into account both the years of education and educational orientation.

The classification of the educational groups was carried out as follows. First, education was divided into two groups according to the length of study (two years and three years). Second, the academic and the vocational streams were separated, and the three-year academic streams further subdivided into two groups: (i) natural science and (ii) the other curricula (mainly social science and languages). Finally, the vocational educational stream was classified into different orientations according to the content of their curricula and the features of the occupations which the education can be expected to lead to, such as artists, technicians, nurses, postal employees and so on. Some educational groups that have very few respondents and that are too different from other groups to be combined with them were omitted, for instance, women educated to be ministers of a faith, customs officers or military officers.

\section{General findings}

\section{Basic findings from the multiplicative model}

Table 1 contains the relative divorce risks for each of the factors derived from a multiplicative model in which there are no interaction terms. The relative risks of every factor can be regarded as standardized for all the other factors taken together. In this section I focus on explaining the effects of age at marriage, parity and premarital preg- 
$\mathrm{T} \mathrm{a} \mathrm{b} \mathrm{l} \mathrm{e} \mathrm{1.} \mathrm{Relative} \mathrm{risks} \mathrm{of} \mathrm{divorce} \mathrm{in} \mathrm{first} \mathrm{marriage} \mathrm{for} \mathrm{Swedish} \mathrm{women} \mathrm{born} \mathrm{in} 1944$ 1963 with a gymnasium education, 1968-1991.

Cohort

$\begin{array}{ll}1944-45 & 1.000 \\ 1946-47 & 1.005 \\ 1948-49 & 0.999 \\ 1950-51 & 1.063 \\ 1952-53 & 1.094 \\ 1954-55 & 1.195 \\ 1956-57 & 1.318 \\ 1958-59 & 1.373 \\ 1960-61 & 1.503 \\ 1962-63 & 1.624\end{array}$

$\begin{array}{ll}\text { Parity } & \\ 0 & 1.000 \\ 1 & 0.442 \\ 2 & 0.229 \\ 3+ & 0.181\end{array}$

Age at marriage

$\begin{array}{ll}20-23 & 1.000 \\ 24-28 & 0.762 \\ 29-35+ & 0.688\end{array}$

Duration of marriage

$\begin{array}{ll}\begin{array}{l}\text { Ordinal years } \\ \text { of marriage }\end{array} & \begin{array}{l}\text { Absol } \\ \text { woma }\end{array} \\ 1-2 & 0.961 \\ 3-4 & 2.945 \\ 5-7 & 3.721 \\ 8-10 & 3.746 \\ 11-14 & 3.611 \\ 15-20 & 3.849\end{array}$

Absolute risk per 1,000 voman-months

0.961

9.945

3.746

3.611

3.849
Premarital birth?

$\begin{array}{ll}\text { no } & 1.000 \\ \text { yes } & 2.427\end{array}$

Pregnant at marriage?

$\begin{array}{ll}\text { no } & 1.000 \\ \text { yes } & 1.470\end{array}$

Relative risks

\begin{tabular}{|c|c|c|c|}
\hline \multicolumn{2}{|c|}{ Relative risks } & \multicolumn{2}{|c|}{ Respondents } \\
\hline 2 years & 3 years & 2 years & 3 years \\
\hline 1.000 & $\begin{array}{l}0.989 \\
0.799\end{array}$ & 19,557 & $\begin{array}{r}16,654 \\
3,249\end{array}$ \\
\hline 1.362 & 1.338 & 993 & 340 \\
\hline 1.412 & 1.516 & 138 & 140 \\
\hline 0.979 & 0.926 & 65,373 & 22,351 \\
\hline 1.352 & 1.101 & 10,462 & 2,617 \\
\hline 2.085 & & 1,422 & \\
\hline 1.003 & 0.873 & 3,774 & 733 \\
\hline 0.813 & 1.185 & 22,604 & 936 \\
\hline 1.042 & & 17,225 & \\
\hline 0.782 & & 22,339 & \\
\hline 0.672 & & 5,998 & \\
\hline 0.983 & & 13,895 & \\
\hline 1.025 & & 3,039 & \\
\hline 1.119 & 0.911 & 1,780 & 497 \\
\hline 0.990 & 1.254 & 14,337 & 413 \\
\hline 1.135 & 0.982 & 488 & 4,370 \\
\hline & & 203,424 & 52,300 \\
\hline & & 255,724 & \\
\hline
\end{tabular}

Educational orientation
Academic streams
1 general gymnasium
2 natural science

Vocational streams

$\begin{aligned} & 3 \text { arts } \\ & 4 \text { driving \& riding instructors } \\ & 5 \text { commerce \& administration } \\ & 6 \text { technicians } \\ & 7 \text { transportation } \\ & 8 \text { postal work } \\ & 9 \text { junior nurse } \\ & 10 \text { nurse's assistant etc. } \\ & 11 \text { child \& youth care } \\ & 12 \text { dental assistant } \\ & 13 \text { medical technician } \\ & 14 \text { social insurance } \\ & 15 \text { agriculture, etc. } \\ & 16 \text { hotel \& restaurant etc. } \\ & 17 \text { beauticians etc. }\end{aligned}$

Sum

Total

\section{Notes}

1. Two-year general gymnasium education. Three-year humanist (liberal-arts) and social-science education, economics, etc.

2. Three-year natural-science education.

3. Education for work in the performing, visual, and musical arts.

4. Education for instructors of physical training (two-year course) and of riding (three-year course). Both two-year and three-year courses include driving-instructor training.

5. Education for secretaries or clerks, or for sales work, computer operators or accountants.

6. Education for skilled workers or technicians in mechanical, manufacturing and forest industries, etc.; also includes laboratory assistants.

7. Education for work in communication and transportation. 
8. Education for work in the post office.

9. Education for lower-grade nurses.

10. Education for hospital and social service.

11. Education for care for children and young teenagers.

13. Education for work as assistants in pharmacies and medical laboratories, or other medical services.

14. Education for general social-insurance services.

15. Education for work in agriculture, horticulture, forestry or fishing.

16. Education for household maintenance, food preparation and restaurant and hotel service and management.

17. Education for hairdressers or beauticians, or for clothes maintenance.

nancy and births, and leave the effects of marital duration, cohort and educational orientation to later sections.

Divorce risks decline as age at marriage increases. This has been shown before for Swedish women by Hoem and Hoem (1992) and Andersson (1994). We also see that women who married at ages $24-28$ and ages $29-35$ have $24 \%$ and $32 \%$ lower divorce risks, respectively, than those who married at ages 20-23. Three explanations of the consistent effect of youthful marriage have been suggested in previous studies. One explanation holds that people who marry at an early age are still seeking independence from the family of orientation. This results in subsequent changes in youngadult role perceptions. Both independence seeking and role changing and their interaction affect the stability of young marriages (Bumpass and Sweet 1972). In contrast, Maneker and Rankin (1985) argue that youthful marriages may have a higher divorce rate not because they have lower marital satisfaction than later marriages, but because they may have more alternatives to the existing marriage and fewer barriers to impede divorce. Becker (1981) assigns this to imperfect information and uncertainties in the marriage market; that is, young people cannot get complete information about their partners' traits and potential earning power and other characteristics that may influence the satisfaction of marriage. Later marriage may imply a longer search period and better information accumulation, which raises marital stability by improving the quality of marital choices. All in all, people who marry young may get less benefit from the current marriage, suffer smaller costs of divorce and have more alternatives outside the marriage, and, hence face a higher divorce risk.

Generally, children are found to be associated with a lower risk of divorce. In terms of economic theory, children are a kind of marriage-specific capital. The accumulation of such capital increases the costs of separation. Sharing collective goods of a marriage such as children may also increase the gains or happiness from marriage. On the other hand, childbearing itself may imply a more stable marriage since a couple with a higher expected probability of divorce may reduce their investment in marriagespecific capital, such as children, and hence raise the risk of divorce (Becker 1981; Weiss, 1993). In this analysis, the inverse relationship between parity and the risk of divorce also strictly holds. The effect of having the first child reduces the divorce probability to virtually half. Further children have similar but diminishing effects.

Premarital childbearing and premarital pregnancy are common in Sweden nowadays, mainly because very few marry without cohabiting first. Such behavior is found to be a strong predictor of first-marriage disruption in all studies of divorce in Sweden (Hoem 1989; Hoem and Hoem 1992; Hoem 1995b; Andersson 1994), as it is also in the current study. Women who have premarital births have a remarkably higher risk of divorce $(143 \%)$ than those who do not have any. Pregnancy at marriage also raises the risk of divorce by $47 \%$. These phenomena may be attributed to two common reasons. First, an unplanned premarital pregnancy or birth may force a couple to marry, even if they are not well matched. Secondly, a woman with a premarital child may be in an unfavorable position in the marriage market if she wants or needs to search for a 
new partner. Her lowered attraction is directly associated with lower perceived rewards from the marriage and thereby a higher probability of marriage dissolution. We also note that a premarital birth has a much stronger effect on divorce than pregnancy at marriage. This is most probably attributed to whether the child is born in the union, a factor that has also been found to influence the risk of divorce (Hoem and Hoem 1992; Bracher et al. 1993). A marriage formed because of pregnancy means a continuation of the same union while woman with a premarital child may marry a man who is not the child's father. Even if it is the same man, the fact that they did not marry before the birth of the child may indicate an unstable relation between the spouses.

\section{The effect of marriage duration}

Duration itself is an important factor affecting the risk of divorce. The divorce risk may decline with the increase of marital duration due to "growing acceptance", that is, couples become increasingly tolerant of each other's faults (Trussell et al. 1992). With Becker's theory, the longer the marital duration, the greater the accumulated marriage-specific capital, the higher the cost of divorce, and hence the lower probability of marriage disruption. There also exists another possibility that the divorce risk rises with the increase of marriage duration because of "accumulated irritation" (Trussell et al. 1992). However, previous Swedish studies support the hypothesis that divorce risks decline with increasing duration of marriage after some years of marriage (Hoem 1995a,b; Andersson 1994).

The life-cycle perspective posits that the effects of causal factors vary with marriage duration (Maneker and Rankin 1985; South and Spitze 1986; Bracher et al. 1993). Divorce may reflect in part the changes in the life cycle. The utility and expectations of marriage may differ at differing stages in the life cycle, and decisions to terminate marriage should also vary accordingly. So, the importance of factors that affect the instability of marriage may change at different stages of marriage. To get a better grasp of possible differentials in the effects of marriage duration across subgroups, I have fitted some hazard regression models with interactions between marriage duration and other factors separately.

The finding from the multiplicative model is surprising because the risk of divorce is nearly constant after the first five years of marriage (Table 1). Within the first five years of marriage, the divorce risk rises rapidly and thereafter remains remarkably stable. To probe into this problem, another multiplicative hazard regression model was fit without controlling the factor of parity. The divorce risks over duration from the new model (not shown here) show a clearly declining trend after the first few years of marriage. Therefore the stable characteristic of the overall risk is attributed to a changing composition of marriages over parities.

The effects of premarital birth and age at marriage do not vary much with the duration of marriage. By contrast, the effects of the number of children exhibit trends that are totally different between the lower parities and higher parities (Figure 1). The divorce risk for women of parity zero and parity one increases quickly in the first phase of marriage and arrives at a peak almost at the same time, although the peak of parity zero is twice as high as that of parity one. After that they show a continued decline and the divorce risk of parity zero approaches the level of parity one. On the other hand, the divorce risks of parities two and three and more show more stable development and have slightly increasing trends all the time. This suggests that children slow the pace at which dissatisfaction is translated to divorce, particularly at the early stage of marriage, but do not prevent divorce entirely. Or, perhaps, those in more stable marriages are more likely to have children. Childless marriages that survive a period of 
elimination have much lower divorce risk during the remaining time of marriage. This may be due mainly to a selective process: the unstable childless marriages are more likely to dissolve during the first few years of marriage; hence, the more stable marriages last longer, providing the basis for selectivity over longer marital duration. It is also possible that some couples in durable but childless marriages may adopt one or a few children and lower their risk of divorce to that of the corresponding parity. All in all, the convergence of the divorce risks across parity in later years of marriage indicates that the effect of marital-specific capital (children) becomes weaker with marital duration. This result partly supports the expectation that marriage serves different purposes at different stages.

\section{The cohort divorce-risk profile}

In a classic paper, Ryder (1965) emphasized the role of cohort analysis in the study of social change. Because of its unique location in the stream of history, each cohort is different from all others in every aspect related to their socialization. The specific composition and historical location of birth cohorts are regarded as important varia-

F i g u r e 1. Divorce risk in first marriage by duration, for each parity; Swedish women with gymnasium education, 1968-91

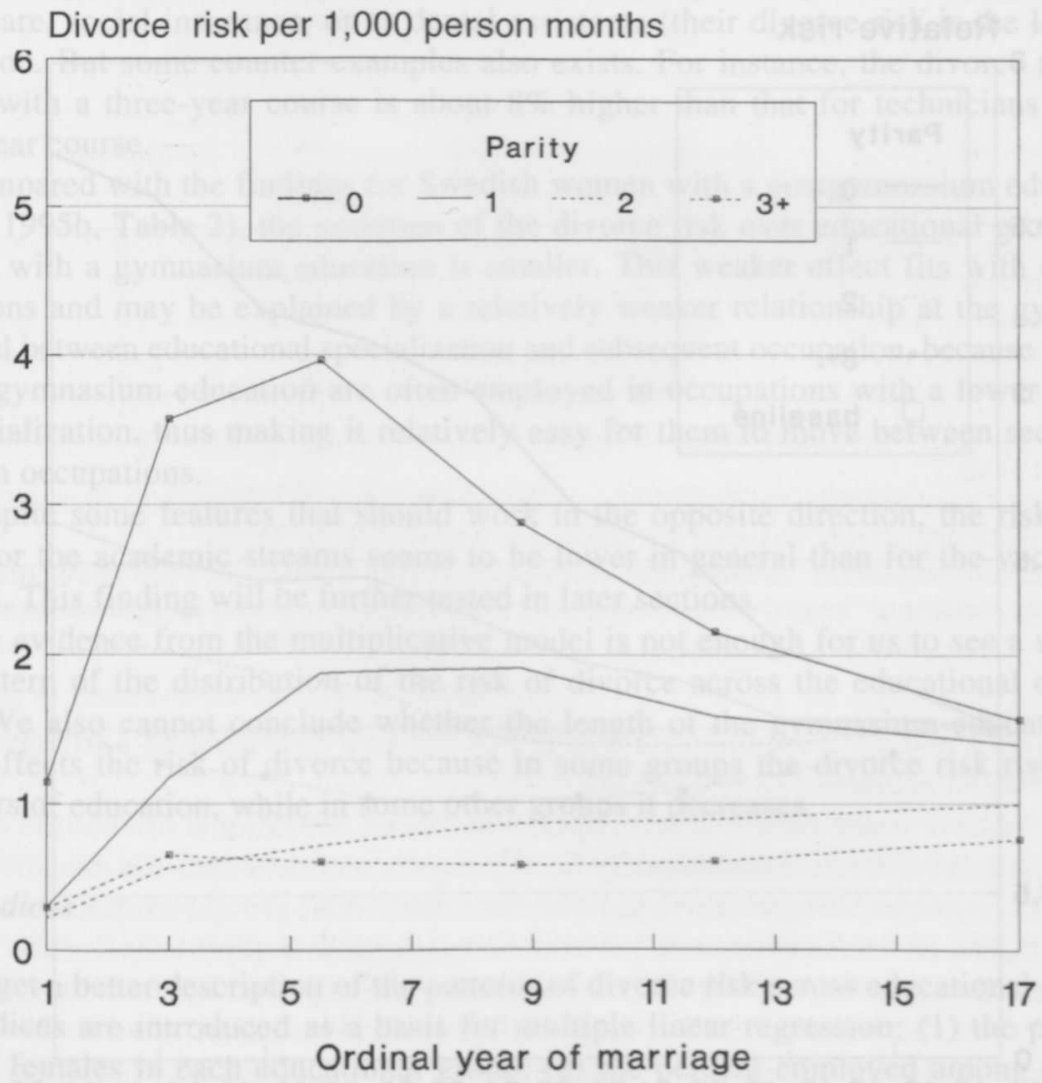

Note: Standardized for cohort, educational orientation, age at marriage, premarital birth, and pregnancy at marriage 
bles in forming values and norms (Van Rijsselt 1989). Changing values, such as increasing emphasis on individual fulfilment and decreasing emphasis on obligation towards family and children are associated with higher divorce risks (England and Farkas 1986, 60-61). Previous studies from Sweden have found an increasing trend of divorce risks over birth cohorts (Hoem and Hoem 1992; Hoem 1995a). But when the study is restricted to women with a postgymnasium education, the divorce risk fluctuates between cohorts, and for different parities the divorce risks show totally different trends by cohorts (Hoem 1995b).

In contrast to the postgymnasium subgroup, the overall trend of divorce risk across cohorts for the gymnasium subgroup conforms with the general trends: it remains stable for the cohorts born in 1944-1949, then increases regularly over subsequent cohorts (Table 1). Decomposing the trend, we find that among the ages at marriage, the younger the age, the higher and more quickly the divorce risk rises over cohorts. (Details are not shown here.) The risk of childless women shows a strongly increasing trend, while the risk of women with two and more children remains relatively stable and even shows a slight decline for the cohorts born before 1955 (Figure 2). This suggests that attitudes and norms concerning obligations to children have not changed dramatically during recent decades in Sweden for women with a gymnasium education, and that marriage cohesion has declined primarily among childless women.

F i g u re 2. Divorce risk in first marriage by cohort, for each parity; Swedish women with gymnasium education, 1968-91

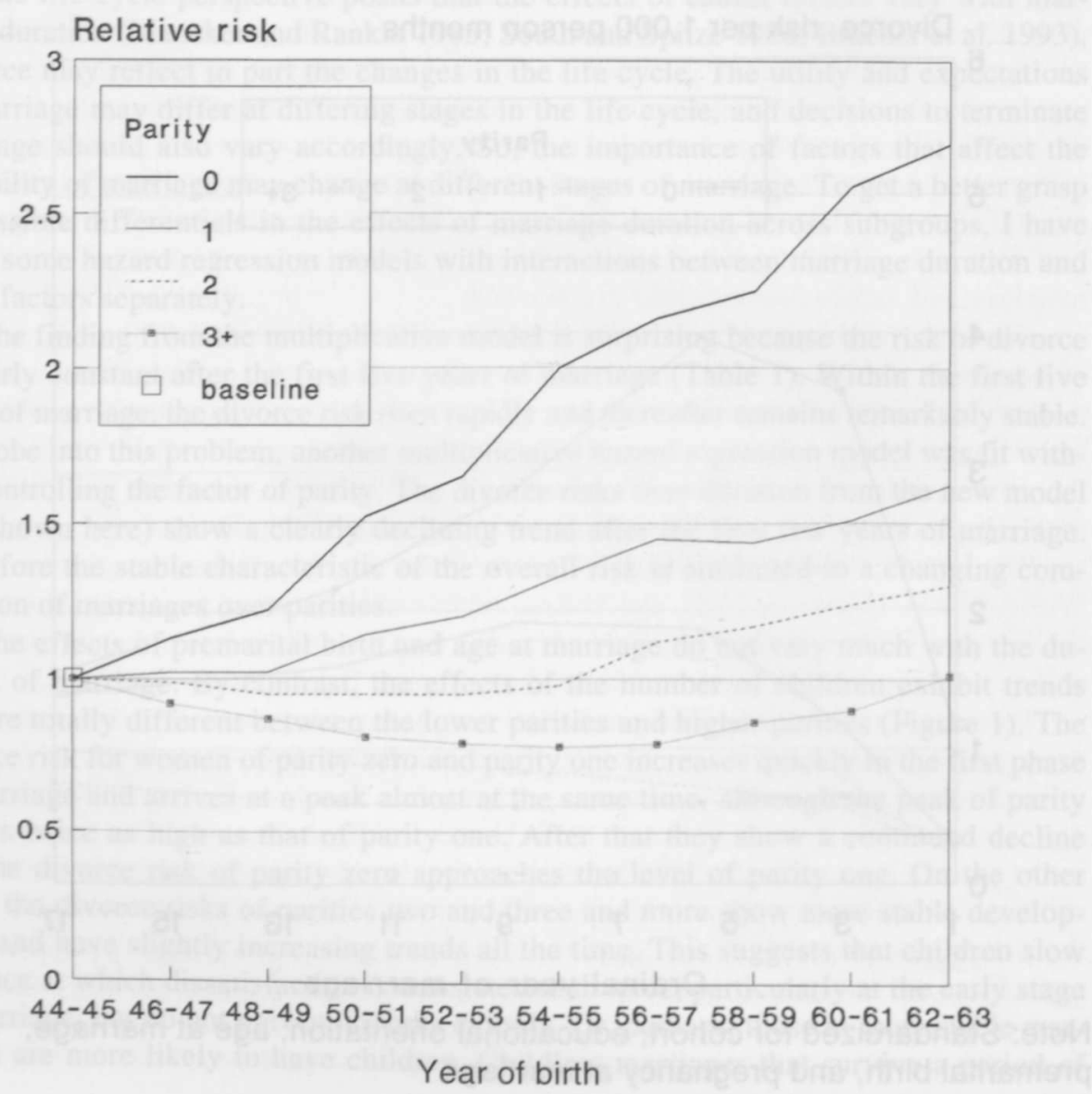




\section{The impact of educational orientation}

Now we turn to the main interest of this analysis. I will first give a brief description of the findings from the hazard regression models. Then two multiple linear regression models are used to further elucidate the patterns of divorce risk across the group with a gymnasium education.

\section{Findings from the hazard regression models}

Besides a multiplicative model in which there are no interactions between the covariates, I have fitted two other models with two-way interactions separately, namely, between educational orientation and marriage duration, and between educational orientation and birth cohort. (They are not shown in this paper.) The effects of educational orientation on divorce risk do not show any consistent patterns of change across birth cohorts, and the patterns according to marriage duration are consistent with the overall trend of divorce risk over duration.

However, the results of the multiplicative model (Table 1) show that, having controlled the effects of birth cohorts, age at marriage, parity, premarital birth and pregnancy at marriage, divorce risks do vary by educational orientation. The results partly support our expectations: women who are educated to work in the arts and for male occupations such as transportation (their divorce risk is the highest), or as driving and riding instructors or technicians, have higher divorce risks than women who are educated for typically female occupations such as nursing (two-year course), child and youth care, social insurance, or as dental assistants (their divorce risk is the lowest), and so on. But some counter-examples also exists. For instance, the divorce risk for nurses with a three-year course is about $8 \%$ higher than that for technicians with a three-year course.

Compared with the findings for Swedish women with a postgymnasium education (Hoem 1995b, Table 2), the variation of the divorce risk over educational groups for women with a gymnasium education is smaller. This weaker effect fits with our expectations and may be explained by a relatively weaker relationship at the gymnasium level between educational specialization and subsequent occupation, because women with a gymnasium education are often employed in occupations with a lower degree of specialization, thus making it relatively easy for them to move between sectors or between occupations.

Despite some features that should work in the opposite direction, the risk of divorce for the academic streams seems to be lower in general than for the vocational streams. This finding will be further tested in later sections.

The evidence from the multiplicative model is not enough for us to see a systematic pattern of the distribution of the risk of divorce across the educational orientations. We also cannot conclude whether the length of the gymnasium education directly affects the risk of divorce because in some groups the divorce risk rises with the years of education, while in some other groups it decreases.

\section{Four indices}

To get a better description of the patterns of divorce risk across educational groups, four indices are introduced as a basis for multiple linear regression: (1) the percentages of females in each educational group; (2) the percent employed among women who graduated from the educational group; (3) the academic or vocational stream of gymnasium education; and (4)the length of gymnasium education. The last two are 
$\mathrm{T}$ a b l e 2. Relative divorce risk in first marriage for Swedish women with a gymnasium education by educational group. Corresponding percentage of females and percentage of women employed for each educational group. Also two dummy variables of the stream and the length of each educational group.

\begin{tabular}{|c|c|c|c|c|c|}
\hline $\begin{array}{l}\text { Educational } \\
\text { groups* }\end{array}$ & $\begin{array}{l}\text { Relative } \\
\text { risks** }\end{array}$ & $\begin{array}{l}\text { Percent } \\
\text { employed }\end{array}$ & $\begin{array}{l}\text { Percent } \\
\text { female }\end{array}$ & Stream ${ }^{* *}$ & Lengt \\
\hline $\begin{array}{l}\text { Academic streams } \\
\text { natural science ( } 3 \text { years) } \\
\text { general gym. ( } 3 \text { years) } \\
\text { general gym. ( } 2 \text { years) }\end{array}$ & $\begin{array}{l}0.799 \\
0.989 \\
1.000\end{array}$ & $\begin{array}{l}71.3 \\
76.2 \\
85.0\end{array}$ & $\begin{array}{l}44.4 \\
68.9 \\
77.9\end{array}$ & $\begin{array}{l}1 \\
1 \\
1\end{array}$ & \\
\hline \multicolumn{6}{|l|}{ Vocational streams } \\
\hline $\begin{array}{l}\text { Two years } \\
\text { technicians } \\
\text { agriculture, etc. } \\
\text { transportation } \\
\text { riding \& driving instr. } \\
\text { arts } \\
\text { postal worker } \\
\text { commerce \& admin. } \\
\text { beauticians etc. } \\
\text { medical technician } \\
\text { hotel \& restaur. etc. } \\
\text { junior nurse } \\
\text { nurse's assistant } \\
\text { child \& youth care } \\
\text { social insurance } \\
\text { dental assistant }\end{array}$ & $\begin{array}{l}1.352 \\
1.119 \\
2.085 \\
1.412 \\
1.362 \\
1.003 \\
0.979 \\
1.135 \\
0.983 \\
0.990 \\
0.813 \\
1.042 \\
0.782 \\
1.025 \\
0.672\end{array}$ & $\begin{array}{l}84.8 \\
84.0 \\
74.5 \\
82.1 \\
75.9 \\
89.9 \\
89.4 \\
81.3 \\
91.2 \\
86.4 \\
92.8 \\
89.7 \\
92.4 \\
89.5 \\
91.4\end{array}$ & $\begin{array}{c}8.6 \\
19.1 \\
23.7 \\
43.7 \\
59.9 \\
65.6 \\
75.5 \\
79.4 \\
83.4 \\
83.5 \\
94.9 \\
95.4 \\
95.7 \\
96.7 \\
99.9\end{array}$ & $\begin{array}{l}0 \\
0 \\
0 \\
0 \\
0 \\
0 \\
0 \\
0 \\
0 \\
0 \\
0 \\
0 \\
0 \\
0 \\
0\end{array}$ & $\begin{array}{l}0 \\
0 \\
0 \\
0 \\
0 \\
0 \\
0 \\
0 \\
0 \\
0 \\
0 \\
0 \\
0 \\
0 \\
0\end{array}$ \\
\hline \multicolumn{6}{|l|}{ Three years } \\
\hline $\begin{array}{l}\text { technicians } \\
\text { agriculture, etc. } \\
\text { arts } \\
\text { riding \& driving instr. } \\
\text { commerce \& admin. } \\
\text { hotel \& restaur. etc } \\
\text { postal worker } \\
\text { junior nurse } \\
\text { beauticians etc. }\end{array}$ & $\begin{array}{l}1.101 \\
0.911 \\
1.338 \\
1.516 \\
0.926 \\
1.254 \\
0.873 \\
1.185 \\
0.982\end{array}$ & $\begin{array}{l}78.1 \\
86.3 \\
77.9 \\
80.7 \\
87.5 \\
87.2 \\
97.4 \\
89.6 \\
85.6\end{array}$ & $\begin{array}{c}7.7 \\
25.2 \\
54.9 \\
56.3 \\
61.4 \\
69.5 \\
69.6 \\
82.4 \\
91.1\end{array}$ & $\begin{array}{l}0 \\
0 \\
0 \\
0 \\
0 \\
0 \\
0 \\
0 \\
0\end{array}$ & $\begin{array}{l}1 \\
1 \\
1 \\
1 \\
1 \\
1 \\
1\end{array}$ \\
\hline
\end{tabular}

* Arranged by increasing percentage of females within each of the three streams of education

** From Table 1.

- Source: Calculated from the Swedish Population and Housing Census of 1990. Folk-och bostadsräkningen 1990, Del 6: Inskomst och utbildning, Table 17. SCB.

*. The dummy variable of "stream" represents whether it is an academic or vocational education. The dummy variable of "length" indicates whether it is a three-year or a two-year gymnasium education.

dichotomies and are coded as in Table 2. For the first two numeric variables, I give more detailed explanations just below.

As we have noted earlier in this paper, whether an educational orientation and corresponding occupation is traditionally female depends on whether it is primarily dominated by women. This gender feature of the educational group is supposed to relate to the degree of conflict between job and marriage, and thereby to influence the stability of marriage. This relationship is expected to be captured by measuring the relation between the percentage of females and the relative risks of divorce for each of the educational orientations.

The conflict between job and marriage is related closely to the extent to which a woman is exposed to the pressure of employment, and the latter is in turn related to 
the activity level of labor force participation and to the sector in which she is employed. For instance, the pressure of a nontraditional job will disappear if a woman leaves the labor force or transfers to a traditional job. An index of "percentage of women employed" among those who graduated from the same educational group is introduced into this analysis in order to catch this feature. This is also done under the assumption that those who are trained for a certain occupation should be more likely to be employed initially in that field than those who are not. A positive gradient in divorce risks according to this index is expected. This hypothesis is in line with the commonly found positive relationship between women's labor force participation and their divorce risks.

Here we need to say some more about the two numeric variables (percent of females and percent employed). Both are derived from the 1990 census data. The percent of females is actually an average level for all the cohorts studied here. It may be overvalued for the old cohorts and undervalued for the younger generations. The percent employed, which is recorded just for the year of 1990, may be overestimated for the old cohorts. However, what we care about in this study is not the exact level of the variables but their general patterns of distribution among the educational groups.

\section{Findings from two multiple linear regression models}

I have used the data of Table 2 to run two separate multiple linear regression models (i) for all the educational groups with all the four independent variables, and (ii) for vocational streams only and without the variable "stream". The results are presented in Table 3.

$\mathrm{T}$ a b l e 3. Results of two multiple linear regression models

\begin{tabular}{lrrrrr}
$\begin{array}{l}\text { Model } 1^{*} \\
\text { Parameters }\end{array}$ & $\begin{array}{c}\text { Percent } \\
\text { employed }\end{array}$ & Percent female & $\begin{array}{c}\text { Variables } \\
\text { Length }\end{array}$ & Stream & Constant \\
$\begin{array}{l}\text { Coefficient } \\
\begin{array}{l}\text { Significance } \\
\text { of T-value }\end{array}\end{array}$ & 0.029966 & -0.001578 & -0.082839 & -0.422438 & 3.829969 \\
$\begin{array}{l}\text { Model } 2 * * \\
\text { Parameters }\end{array}$ & $\begin{array}{r}\text { Percent } \\
\text { employed }\end{array}$ & Percent female & Length & Constant & \\
$\begin{array}{l}\text { Coefficient } \\
\text { Significance }\end{array}$ & -0.035569 & -0.001290 & -0.037348 & 4.276603 & \\
of T-value & 0.0007 & 0.4834 & 0.00000 & \\
\hline
\end{tabular}

* All the 27 groups of education are included.

** Only the 24 groups of vocational education are included.

The regression that involves all groups shows again that women from academic gymnasium streams have significantly lower divorce risks than those from vocational streams. This might imply a changing pattern of divorce among women with different socioeconomic background since the early 1980 s, but such a possibility needs to be tested further in a different analysis.

The length of education shows a negative but not significant relation to the risk of divorce in both of the two models. It seems that the length of education is not sufficiently important to significantly influence the risk of divorce. This may be because a 
single year's difference in educational attainment is too small to have any important effect on the divorce risk.

The coefficient of the percentage of females in each educational group has a negative sign, but it is not statistically significant in either of the models. Perhaps this is because the supposed gender features of educational orientation and corresponding occupation cannot be represented by a single indicator (percentage of females in each educational group in 1990), for their linkage may not be as strong as we have assumed. However, if we compare typically male occupations (percentage of females lower than $50 \%$ ) with typically female occupations (percentage of females higher than $80 \%$ ), the divorce risks are much higher for women educated for typically male occupations (the relative divorce risks are from 1.101 to 2.085 except for the 3-year agricultural course) than women educated for typically female occupations (the relative divorce risks are from 0.672 to 1.042 except for the 3 -year nurse's training). So what makes the pattern complex are the "neutral" occupations. In these groups, for most of the occupations, different statuses of the same occupation may have different gender features. For example, in hotel and restaurant work, the job of a kitchen worker may be dominated by men while other services are done mainly by women. So the vague effect of the gender features of vocational educational groups may also result from an inexplicit gender orientation in these occupations as a whole.

To our surprise, we find a significantly negative relationship between the divorce risk and the percentage of women employed in each educational group, both when academic streams are included and when they are not. This is in contrast to a common hypothesis, which suggests a positive relationship between divorce and women's labor force participation. I can think of three possible explanations of this negative relationship. First, women who are not employed may have more problems than others with their mental or physical health. Being a housewife in a society where most women have a job may lead to loneliness and depression, and may make the woman feel that she can achieve greater control over her life if she divorces (Levinger 1979,57). Alternatively, primary personal problems may lead individuals to be out of the labor market and also to be more divorce-prone. Second, employed women may get a wider and wiser perspective on things than housewives do. They may also be more positive toward life as well as toward marriage. Third, because the Swedish public-policy system encourages married women to pursue gainful employment, and since Sweden combines a high rate of female labor force participation with a relatively high fertility (Sundström, 1992), the conflict between the roles of worker, on the one hand, and wife and mother, on the other hand, may be less for Swedish women than for other women. As a consequence, the effects found in other populations may be weaker in Sweden.

Another likely possibility also exists, namely that our result does not contradict the common findings based on the data at the individual level where a woman's labor force participation makes her more likely to divorce. The negative relationship we find here is at the aggregate level and refers to the average divorce risk and average employment level of each educational group. This means that it depends both on the individual relation between employment and divorce risk, and on the distribution of individuals within each educational group. We cannot simply transfer the relation we find at the aggregate level in support of a hypothesis that the same relation holds for the individuals. To do so would be to commit an "ecological fallacy".

Even if a positive relation between female labor force participation and divorce risk holds at the individual level, the negative relation we find at the aggregate level may still be reasonable. The positive relation at the individual level results mainly from conflicts between job and marriage. These depend both on labor force participation itself, and also on the sector of employment or on occupation. Women who are employed initially in nontraditionally female occupations are more likely to suffer con- 
flicts between job and marriage. For these women, there are several alternatives: (1) stick to the current job but suffer a higher risk of divorce; (2) withdraw from the labor force to avoid divorce; (3) transfer to a traditionally female job in order to reduce the conflict. It is not possible for everybody to successfully carry out the last option, however, because changing jobs is not costless and those who are not originally trained for traditionally female jobs will be at a disadvantage in that section of the labor market. Some women who fail to transfer to new jobs have to withdraw from the labor force if they want to protect their marriage. Therefore, women who are educated for nontraditionally female occupations may be more likely to withdraw from labor force and are also more likely to suffer a higher risk of divorce. This is consistent with the negative relation observed between the percent employed and the divorce risk.

\section{Conclusions and discussion}

The general patterns of first-marriage divorce risks for Swedish women with a gymnasium education are consistent with previous studies: divorce risks decrease strongly with an increasing age at marriage and with increasing parity, and those who have premarital children or are pregnant at marriage have higher divorce risks than those who do not. The divorce risk increased over the cohorts born during 1948-1963.

Having children strongly stabilizes marriage for women with a gymnasium education, but its effect becomes weaker as marriage duration increases. Norms concerning obligations to children have not changed dramatically during the decades under study, and marriage cohesion has declined primarily among the childless.

An important finding is that divorce risks vary by educational orientation, although not as much as what has been found for Swedish women with a postgymnasium education. There is no systematic pattern according to the length of the gymnasium education, but women who graduated from an academic stream seem to have lower divorce risk than women graduated from vocational streams.

A surprising finding is that women who have graduated from the gymnasium in a field with a relatively high female labor force participation are less likely to divorce than women graduated from the gymnasium with a relatively low level of labor force participation. This may not contradict the common hypothesis based on individual information that women's employment leads to a higher risk of divorce, but may reflect some effect on the divorce risk of the orientations of education and of the corresponding occupations.

We cannot find a significantly negative relationship between the percentage of females in each of the educational groups and the risk of divorce. However, there is evidence of some effects of the gender features of an educational group: for women educated for nontraditionally female occupations, the divorce risk is clearly higher than for women educated for traditionally female occupations. So we have reason to argue that, to some extent, a woman's choice of educational orientation may act as a visible influence on her risk of divorce. Women with stronger gender-equality norms are more likely to seek to be educated for occupations that are not traditional for women. But women in nontraditional jobs are also more likely to suffer conflicts between job and marriage. So they are more likely to be in a dilemma: to avoid divorce they may have to leave the labor force or move to a traditional job. Both leaving the labor force and changing occupations are costly and imply some kind of sacrifice for the woman. Whether the result of the cost-benefit rationality is to sacrifice her career for the marriage or the opposite ultimately depends partly on whether she is more family oriented or more career oriented. Thus the negative relationship between the divorce risk and the percent employed in each educational group may reflect the effect of gender 
features of educational orientation on divorce risk more than the effect of employment. Even if it is the characteristics of the occupation that influence the risk of divorce, this process may start earlier - it may start already at the time when a woman elects to be educated towards certain occupations.

The conclusion of this paper is suggestive rather than definitive. The difficulty in investigating the relationship between women's educational orientation and divorce risk results from the intermediate role of occupational experience. Due to limited information in our data, we can only suggest that there seems to exist a relationship between educational specialization and divorce risk for Swedish women with a gymnasium education. This needs to be further tested by using additional information about the employment experiences of women after completion of gymnasium education.

\section{Acknowledgements}

I am indebted to Jan M. Hoem who supervised me when I did this study and to Michael Bracher who gave me great help in improving the analysis. I also thank Marianne Sundström and Frances K. Goldscheider for their valuable suggestions and comments. I have also got valuable comments from my colleagues in the Demography Unit of Stockholm University.

\section{References}

Andersson, Gunnar. 1994. Divorce risk trends in Sweden 1971-1993. European Journal of Population 11(4):293-311.

Becker, Gary S. 1981 (1991). A Treatise on the Family. Cambridge, MA: Harvard University Press.

Blossfeld, Hans-Peter, Alessandra De Rose, Jan M. Hoem, and Götz Rohwer. 1993. Education modernization, and the risk of marriage disruption: differences in the effect of women's educational attainment in Sweden, West-Germany, and Italy. Stockholm Research Report in Demography No. 76. Stockholm: Stockholm University.

Bracher, Michael, Gigi Santow, S. Philip Morgan and James Trussell. 1993. Marriage dissolution in Australia: models and explanations. Population Studies 47(3):403-425.

Bumpass, Larry L. and James A. Sweet. 1972. Differentials in marital instability: 1970. American Sociological Review 37:754-766.

England, Paula and George Farkas. 1986. Households, Employment, and Gender: A Social, Economic and Demographic View. New York.: Aldine.

Hoem, Britta and Jan M. Hoem. 1992. The Disruption of marital and non-marital unions in contemporary Sweden. In: Demographic Applications of Event History Analysis, edited by James Trussell, Richard Hankinson, and Judith Tilton, pp. 61-93. Oxford. Clarendon Press.

Hoem, Jan M. 1991. Trends and patterns in Swedish divorce risks 1971-1989: a case of modern demographic analysis. Stockholm Research Reports in Demography No. 64. Stockholm: University of Stockholm.

-. 1995a. Educational gradients in divorce risks in Sweden in recent decades. Stockholm Research Reports in Demography No. 84. Stockholm: University of Stockholm. To appear in Population Studies, 1997.

-. 1995b. Educational capital and divorce risk in Sweden in the 1970s and 1980s. Stockholm Research Reports in Demography No. 78. Stockholm: Univesity of Stockholm.

-. 1995c. Harmfulness or harmlessness of using an anticipatory regressor: how dangerous is it to use education achieved as of 1990 in the analysis of divorce risks in earlier years? Paper presented to the 11th Nordic Demographic Symposium, Helsinki, June 1995.

Houseknecht, Sharon K. and Graham B. Spanier. 1980. Marital disruption and higher education among women in the United States. Sociological Quarterly 21(3):375-389.

Levinger, George. 1979. A social psychological perspective on marital dissolution. In Divorce and Separation, edited by George Levinger and Oliver C. Moles. New York. Basic Books Inc.

Maneker, Jerry S. and Robert P. Pankin. 1985. Education, age at marriage, and marital duration: is there a relationship? Journal of Marriage and the Family 47(3):675-683. 
Philliber, William W. and Dana V. Hiller. 1983. Relative occupational attainments of spouses and later changes in marriage and wife's work experience. Journal of Marriage and the Family 45(1):161-170.

Ryder, Norman B.. 1965. The cohort as a concept in the study of social change. American Sociological Review 30:843-861.

SCB, Statistiska Centralbyrån (Statistics Sweden). 1995. Kvinnors och mäns liv. En rapport från SCB:s undersokning om Familj och Arbete, 1995:2.1.

South, Scott J. and Glenna Spitze. 1986. Determinants of divorce over the marital life course. American Sociological Review 51:583-390.

Sundström, Marianne and Frank P. Stafford. 1992. Female labor force participation, fertility and public policy in Sweden. European Journal of Population 8(3):199-215.

Trussell, James, Germán Rodríguez, and Barbara Vaughan. 1992. Union dissolution in Sweden. In: Demographic Applications of Event History Analysis, edited by James Trussell, Richard Hankinson, and Judith Tilton, pp. 38-60. Oxford: Clarendon Press.

Van Rijsselt, R. 1989. Developments in attitudes and value orientations - a comparison between birth cohorts in the Netherlands over the period 1970-1985. Paper prepared for the Symposium on Life Histories and Generations, Netherlands Institute for Advanced Studies, Wassenaar, June, 1989.

Weiss, Yoram. 1993. The formation and dissolution of families: Why marry? Who marries whom? And what happens upon marriage and divorce. Working Paper No. 15, Foerder Institute for Economics, Tel-Aviv University.

White, Lynn K.. 1990. Determinants of divorce: a review of research in the eighties. Journal of Marriage and the Family 52(4):904-912. 